\title{
CONSIDERAÇÕES SOBRE O METAMORFISMO DAS ROCHAS DA REGIÃO DE EMBU-GUAÇU - PARELHEIROS, SP
}

\author{
SÍLVIA R.S.S. VIEIRA*, JOSÉ M.V. COUTINHO* e FRANCISCO R. ALVES*
}

\begin{abstract}
SOME COMMENTS ON THE METAMORPHISM OF ROCKS FROM THE EMBU-GUAÇU PARELHEIROS REGION, SP. The study of rocks related to Pilar Complex of the Açungui Group, which occur immediatelyto the SSE of São Paulo, revealed the existence of four distinctmetamorphic episodes. The first one, regional in scale and progressive in character, attained its peak at temperatures around $700^{\circ} \mathrm{C}$ and pressure over $5,5 \mathrm{kbar}$, compatible with amphibol ite fades or medium grade conditions. The second episode, also regional in scale, was probably a metasomatic event, promoted by aqueous acidic (low $\mathrm{pH}$ ), B and K-rich solutions, remanents of former magmatic activity. The third episode, a retrograde one, was brought about by the adaptation of high P/T assemblages, ascribable to $\mathrm{M}$ l, to milder conditions, whilstthe forth one corresponds to astructural and textural answer of rocks to movements along the fault zones.
\end{abstract}

Keywords: Regional metamorphism, metasomatism, retrograde metamorphism, Pilar Complex, Acungui Group, Geochronology, São Paulo city, Embu-Guaçu, Parelheiros.

\begin{abstract}
RESUMO O estudo de rochas atribuídas ao Complexo Pilar do Grupo Açungui, que ocorrem imediatamente a SSE da cidade de São Paulo, revelou a existência de quatro episódios distintos de metamorfismo. O primeiro, regional e progressivo, atingiu seu pico a temperaturas em torno de $700^{\circ} \mathrm{C}$ e pressões maiores que $5,5 \mathrm{kbar}$, compatíveis com a fácies anfibol ito. O segundo episódio, também regional, foi provavelmente um evento metassomático, promovido por sol uções aquosas ácidas (pH baixo), ricas em B e K, residuais da atividade magmática anterior. O terceiro episódio, retrógrado, representa a adaptacão das assembléias de altas $\mathrm{P} / \mathrm{T}$, geradas durante o primeiro evento, acondições mais brandas. $\mathrm{O}$ quarto corresponde a modificações estruturais e texturais das rochas em respostaà movimentação ao longo de zonas de falhas.
\end{abstract}

Palavras-chaves: Metamorfismo regional, metassomatismo, metamorfismo retrógrado, Complexo Pilar, Grupo Açungui, Geocronologia, cidade de São Paulo, Embu-Guaçu, Parelheiros.

INTRODUÇÃO Enquanto os estudos sobre as estruturas das rochas pré-cambrianas de São Paulo têm se desenvolvido nos últimos anos, os estudos sobre os processos metamórficos que as afetaram têm sido relegados a segundo plano.

Isto se deve, em parte, ao estado de alteração destes materiais e às dificuldades que envolvem o estudo de rochas intemperizadas.

Se a alteração é um fator limitante à identificação de associações paragenéticas, é possível, conforme demonstrou Coutinho (1972), chegar a algumas conclusões sobre a evolução metamórfica destas áreas, com o auxílio de técnicas simples e ainda pouco utilizadas.

Nesse contexto, este trabalho, realizado em região de rochas intensamente intemperizadas, traz esboço e algumas considerações, inclusive com inferências sobre as condições de pressão e temperatura, sobre a sucessão dos eventos metamórficos que atuaram sobre as seqüências metassedimentares que afloram na região de Embu-Guaçu - Parelheiros.

LOCALIZAÇÃO DA ÁREA A área estudada compreende parte da Grande São Paulo e os municípios de Itapecirica da Serra, Embu-Guaç e Juquitiba, correspondendo a polígono regular de aproximadamente $480 \mathrm{~km}$, situado a SSE da capital paulista (Fig. 1).

MATERIAIS E MÉTODOS Todo o trabalho foi baseado em observações petrográfícas realizadas tanto em amostras sãs quanto alteradas.

As rochas sãs foram estudadas em seções delgadas, de acordo com os métodos petrográfícos convencionais.

Rochas intemperizadas, mas ainda suficientemente compactas, foram impregnadas segundo técnica proposta por Parisot et al. (1985), e posteriormente laminadas.

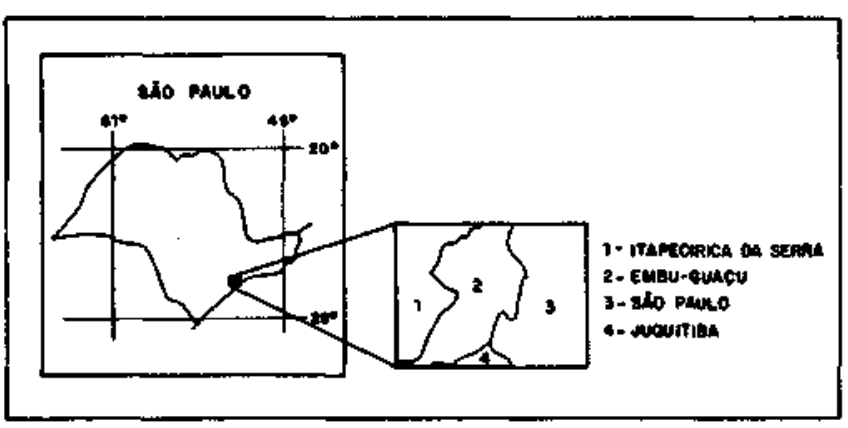

Figura 1 - Localização da área estudada. O destaque mostra sua divisão administrativa

Figure 1 - Localization ofthe studied area. Insetshows its administrative division

Materiais mais alterados, correspondendo já a solo estruturado e autóctone, foram lavados para eliminação de argila; as frações mais grossas foram descritas ao microscópio, com o auxílio de líquidos de imersão convenientes.

Amostras de subsuperfície, conseguidas a partir de testemunhos de sondagens rotativas, gentilmente cedidas pela Companhia Energética de São Paulo (CESP), foram fundamentais à pesquisa.

TRABALHOS ANTERIORES São escassos os trabalhos sobre o metamorfismo das unidades metassedimentares paulistas e, entre elas, a maior parte consistindo em notas sobre a ocorrência de minerais metamórficos e em observações petrográfícas, tendo em vista o estabelecimento de uma 

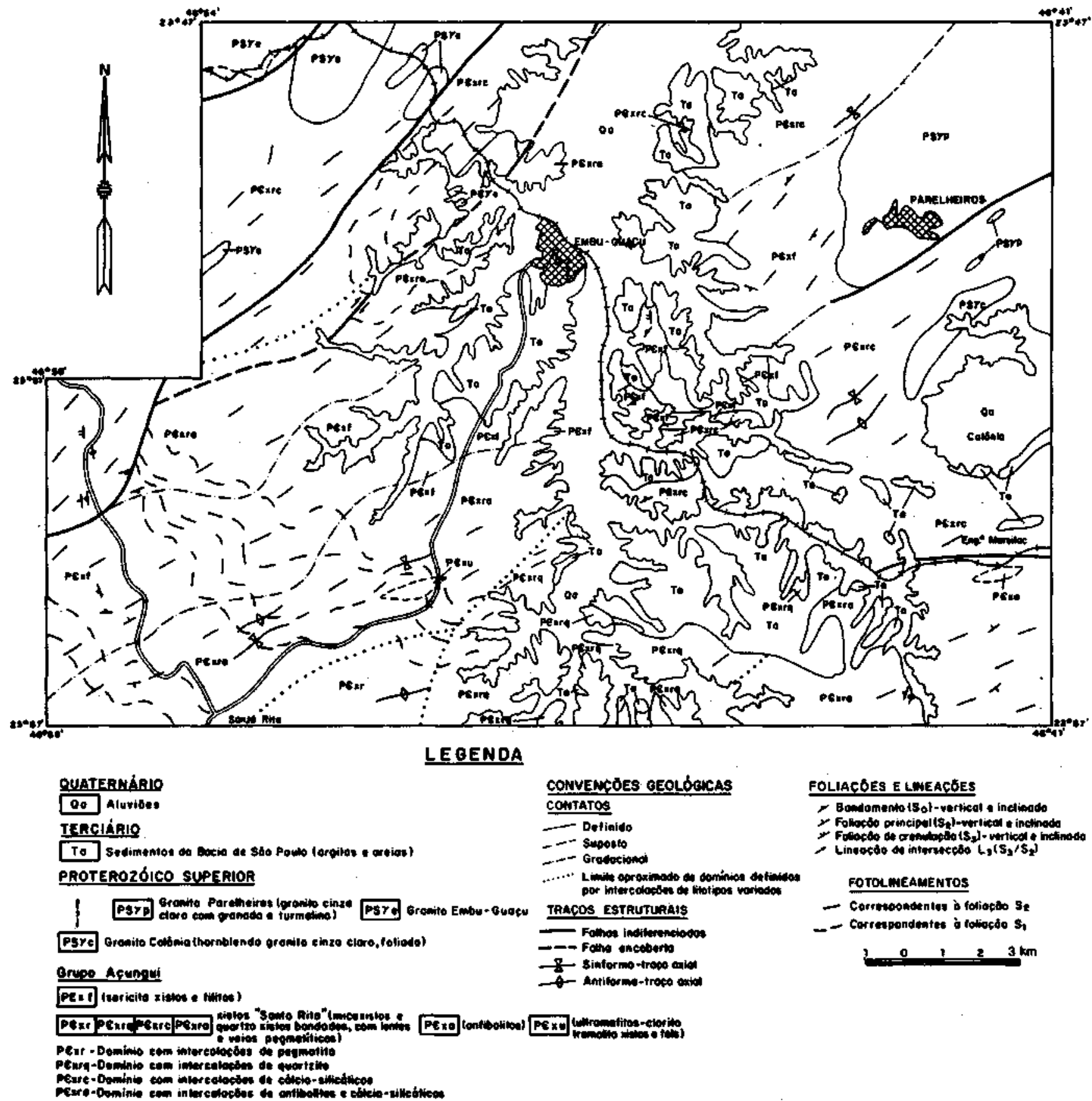

FOLIACOESS E LWEACÖES

- Bomlomento isot-vertical a incliondo

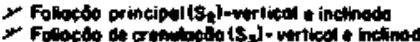

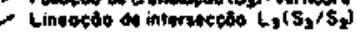

\section{FOTOLMEAMENTOS}

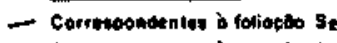
- Corretpondiontes do loliosio $s$,

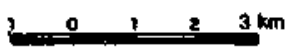

Figura 2 - Mapa geológico da região de Embu-Guaçu - Parelheiros (simplificado de Vieira 1989) Figure 2 -Geological map of the Embu-Guacu-Parelheiros region (simplified from Vieira 1989)

cronologia relativa entre metamorfismo e deformação. Praticamente, inexistem estudos de cunho petrológico.

Exceção é o trabalho de Coutinho (1972), que, mapeando a porção sul da cidade de São Paulo, caracterizou isógradas de biotita, de almandina, de estaurolita e de sillimanita, além de ocorrências isoladas de andaluzita, relacionadas a metamorfismo de contato.

A ausência de cianita, então só descrita em concentrados de minerais pesados provenientes de saprolitos (Coutinho 1972, Suguio et al. 1972), fez com que as condições de metamorfismo desse conjunto fossem comparadas às de New Hampshire, onde as pressões são inferiores àquelas próprias das seqüências do tipo Barroviano. No trabalho de Coutinho (1972), foram ainda definidos um evento de metamorfismo regional, em condições dos fácies xisto verde e anfibolito, um evento de contato e um evento retrógrado; foi sugerido, também, evento metassomático que propiciaria a formação de muscovita e sillimanita fibrosa, por adição de potássio e de turmalina, por adição de boro.

Hasui (1973) e Hasui \& Sadowski (1976) reforçaram as idéias de Coutinho (1972) e estabeleceram uma cronologia relativa entre metamorfismo e deformação. Assim, o metamorfismo regional progressivo foi admitido como sincrônico à primeira fase de deformação; o de contato, como contemporâneo às intrusões sintectônicas à segunda fase de deformação, seguido, já em condições pós-tectônicas, pelo metamorfismo retrógrado.

Stein (1984) e Stein et al. (1986) postularam para as rochas da Folha de Pilar do Sul dois eventos regionais: o primeiro, em grau médio a forte, contemporâneo à primeira fase de defor- 

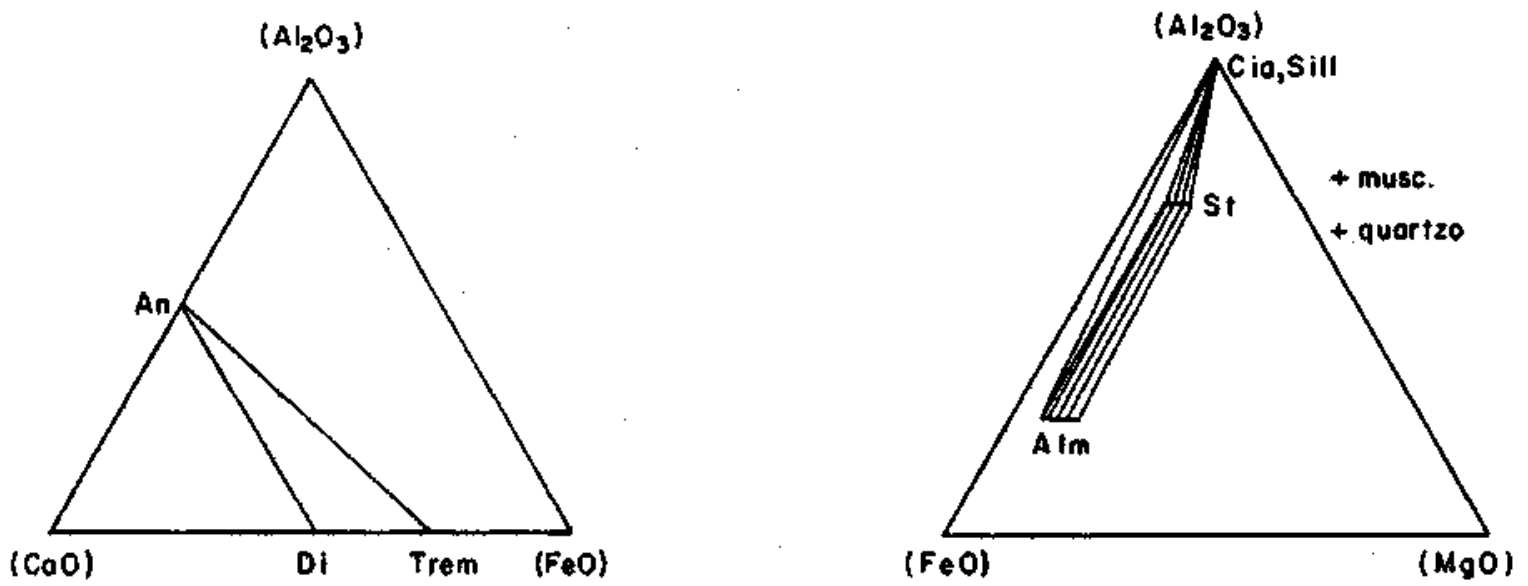

Figura 3 a - Representação em diagrama ACF das paragêneses descritas em rochas cálcio-silicáticas da região de Embu-Guaçu - Parelheiros, compatíveis com o fades anfibolito ou grau médio

Figure 3a - ACF diagram representation of mineralogical paragêneses described in calc-silicate rocks from the Embu-Guacu-Parelheiros region, compatible with amphibolite facies or medium grade metamorphic conditions

Figura 3 - Idem, em diagrama AFM, para as rochas metapeliticas

Figure $3 \mathrm{~b}$ - As in 3a, but in afm diagram for metapelitic rocks

mação, e o segundo, em grau fraco a médio, posterior à primeira fase de deformação e responsável pela gênese de porfiroblastos de andaluzita, clorita e biotita.

GEOLOGIA LOCAL A área em questão encontra-se inserida nos domínios do Bloco Juquitiba, sendo, do ponto de vista tectônico, parte do Sistema de Dobramento Apiaí (Hasui et al 1978, Campanha et al 1987), um dos componentes da região de Dobramentos Sudeste (Hasui et al 1978).

Suas rochas foram inicialmente atribuídas ao Grupo Açungui, subdividido por Hasui \& Sadowski (1976) em dois complexos litológicos: um migmatítico, denominado Embu, e ectinítico, denominado Pilar.

Estudos de maior detalhe, realizados na região de EmbuGuaçu - Parelheiros (Vieira 1989), levaram à opção pela inclusão de todas as rochas que ali afloram no Complexo Pilar, já que não foram encontrados migmatitos e nem foram atingidas, regionalmente, as condições de anatexia.

A geologia local, descrita com mais detalhe em Vieira (1989) e Vieira et al (1990), consiste em seqüências précarnbrianas representadas pela unidade dos xistos rítmicos informalmente denominada "Santa Rita" (Vieira 1989, Vieira et al 1990) -, pela unidade dos sericita xistos e filitos e pelos Granites de Embu-Guaçu, Parelheiros e Colônia. Superpostos, ocorrem sedimentos terciários da Bacia de São Paulo e aluviões quaternários (Fig. 2).

A unidade "Santa Rita" é predominante na área, constituindo-se de micaxistos e quartzo xistos em estratos, com espessura rnédia de $30 \mathrm{~cm}$, alternados ritmicamente. Intercalados, de forma subordinada, ocorrem níveis decimétricos concordantes de rochas cálcio-silicáticas, anfibolíticas e metaultramáficas, que permitem subdividir a unidade em domínios litológicos a partir da freqüência com que estes tipos se apresentam.

Localmente, como nos arredores de Santa Rita e Engenheiro Marsilac, as rochas metaultramáficas e anfibolíticas, respectivamente, atingem dimensões métricas.

Pegmatites com dimensões variadas, desde centimétricos a decamétricos, são onipresentes.

A unidade dos sericita xistos e filitos aflora em meio à unidade dos xistos "Santa Rita" como faixa com direção geral NE, constituída por metassedinientos finos, com granulação - à exceção dos porfiroblastos - invisível a olho nu, homogêneos, quase isentos de intercalações.

Tanto os xistos "Santa Rita" quanto os sericita xistos e filitos mostram estratificação reliquiar dobrada e redobrada por sucessivos episódios de deformação, sendo o segundo responsável pela foliação regional mais expressiva.

A primeira fase de deformação encontra-se materializada por clivagem ardosiana, dificilmente reconhecida, dada sua intensa crenulação e transposição provocada pela atuação de uma fase posterior, caracterizada por clivagem de crenulação diferenciada e por um bandamento tectônico submilimétrico.

A terceira fase de deformação é evidenciada através de uma clivagem de crenulação espaçada e de ocorrência mais local, sendo também responsável pelas dobras mesoscópicas que ocorrem na região.

META MORFISMO As rochas da região de Embu-Guaçu - Parelheiros forarn afetadas por quatro episódios de metamorfísmo: o primeiro, de caráter regional e progressivo; o segundo, interpretado como metassomático; o terceiro, retrógrado; e o quarto, cataclástico, associado a falhamentos transcorrentes.

Metamorfismo regional progressivo $M_{1} O$ metamorfismo regional progressivo Mi diminui de intensidade em direção à unidade dos sericita xistos e filitos.

O grau de metamorfismo que atuou sobre esta última unidade não pôde ser caracterizado com segurança devido à alteração intensa que impede estudos petrográficos de maior detalhe sobre suas rochas. Além disso, como as sondagens efetuadas na área não atingiram esta seqüência, não foi possível dispor de amostras mais preservadas que permitissem tais análises.

Assim, a atribuição de um grau metamórfico mais baixo para unidade é feita a partir da granulometria fina de suas rochas e esta inexistência de minerais típicos de grau metamórfico mais elevado, resistentes ao intemperismo, como, por exemplo, sillimanita.

$\mathrm{Na}$ unidade dos xistos "Santa Rita" foram identificadas associações minerais - nos xistos propriamente ditos e nas rochas cálcio-silicáticas - condizentes com as esperadas para o grau médio (Winkler 1977) ou para o fácies anfibolito (Winkler 1967).

Entre essas, são significativas: diopsídio + tremolita + anortita, diopsídio + tremolita + granada, estaurolita + cianita + sillimanita + almandina + quartzo (Fig. 3 ), todas possíveis dentro do campo de estabilidade da estaurolita (Richardson 1968, Hoscheck 1969, Ganguly 1972). 


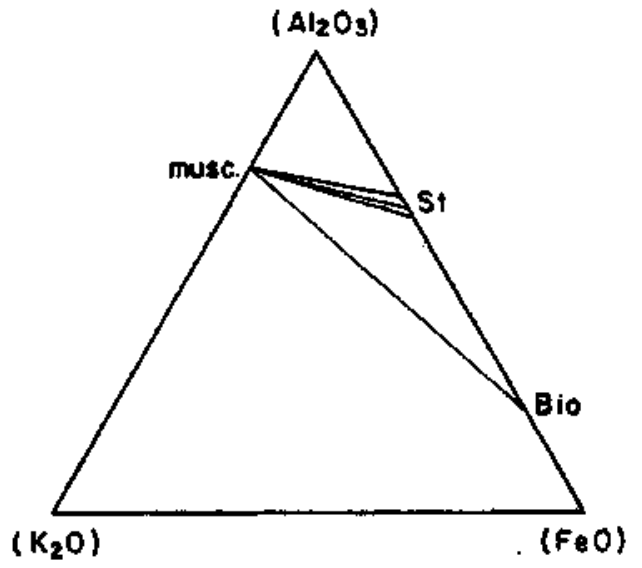

Figura 4 - Representação em diagrama AKF da associação "estaurolita+muscovita+biotita" descrita nos xistos rítmicos dos arredores de Santa Rita

Figure 4 - AKF diagram representation of the "staurolite+muscovite+biotite" association described in the rythmic schists from Santa Rita

O campo de estabilidade da estaurolita tem sido objeto de estudo de vários pesquisadores e várias reações têm sido propostas para definir seus limites. Algumas dessas, postuladas para sua geração, ou seja, como limite inferior de seu campo de equilíbrio, envolvendo o desaparecimento de clorita (Hoscheck 1969) ou cloritóide rico em ferro (Richardson 1968) em presença de muscovita ou sillimanita, respectivamente.

Já, para o desaparecimento da estaurolita, ou seja, para o limite superior de seu campo de estabilidade, as reações comumente propostas baseiam-se em sua desintegração em presença de quartzo + muscovita, resultando no aparecimento de almandina (Richardson 1968, Ganguly 1972) ou biotita (Hoscheck 1969), sempre acompanhadas deumaluminossilicato.

As condições de equilíbrio para as várias reações são compatíveis e, em conjunto, permitem delimitar um campo de coexistência estável entre "estaurolita+quartzo+muscovita", restrito a um intervalo máximo de $200^{\circ} \mathrm{C}$ e pouco afetado pela pressão, o que faz com que a estaurolita possa ser utilizada como indicadora de temperatura do evento que a originou.

As paragêneses estaurolita + biotita + opacos e estaurolita + biotita + muscovita (Fig. 4), descritas nos xistos próximos a Santa Rita, favorecem a adoção da reação clorita+muscovita $<=>$ estaurolita + biotita + quartzo $+\mathrm{H}_{2} \mathrm{O}$ (1) (Hoscheck 1969), como a que melhor representa o processo de geração da estaurolita. Suas condições de equilíbrio estabelecem-se a $540^{\circ} \mathrm{C}+15^{\circ} \mathrm{C}$ a $4 \mathrm{kbar}$ e $565^{\circ} \mathrm{C}+15^{\circ} \mathrm{C}$ a $7 \mathrm{kbar}$, definindo uma curva que é tida por Winkler (1977) como a que marca a transição entre os fácies xisto verde e anfíbolito ou entre os graus fraco e médio, correspondendo, na região, às condições $\mathrm{m}$ ín imãs para o pico do metamorfismo regional progressivo Mi.

Por outro lado, parageneses envolvendo estaurolita + cianita + sillimanita + quartzo, estaurolita + biotita + cianita + opacos e estaurolita+biotita+muscovita (Fig. 5) podem ser indicativas de pressões e temperaturas compreendidas no campo de estabilidade da associação "estaurolita+muscovita+quartzo" que, englobando o ponto triplo do sistema $\mathrm{Al}_{2} \mathrm{SiOs}$, permite a presença, em equilíbrio, de qualquer dos polimorfos com esta assembléia, ou podem ser indicativas de condições idênticas às da reação de quebra da estaurolita.

Richardson (1968) e Ganguly (1972) identificaram granada e aluminossilicato como produto desta desintegração. Embora os xistos "Santa Rita" tenham almandina como mineral freqüente, não existem evidências texturais que possam dar respaldo a esta idéia, parecendo mais razoável explicar as parageneses acima descritas a partir da reação estaurolita + muscovita + quartzo $\leftarrow \rightarrow$ aluminossilicato + biotita $+\mathrm{H}_{2} \mathrm{O}(2)$, proposta por Hoscheck (1969), e que tem seu equilíbrio representado pela curva balizada por $575^{\circ} \mathrm{C}+15^{\circ} \mathrm{C}$ a 2 kbar e $675^{\circ} \mathrm{C}^{\prime}+15^{\circ} \mathrm{C}$ a $5,5 \mathrm{kbar}$.

As assembléias de rochas cálcio-silicáticas intercaladas aos xistos "Santa Rita" reforçam estas conclusões. Nelas foram identificadas parageneses com: anortita + epídoto + tremolita, anortita + epídoto + diopsídio, anortita + epídoto + calcita, anortita + epídoto + granada, anortita + tremolita + granada, anortita + epídoto + diopsídio, granada + epídoto + diopsídio, granada + epídoto + tremolita (Fig. 6), também possíveis no campo de estabilidade da estaurolita.

Duas equações podem expressar as associações acima descritas: zoisita + quartzo $\longleftrightarrow \rightarrow$ granada + anortita $+\mathrm{H}_{2} \mathrm{O}$ (3) e tremolita + calcita + quartzo $\longleftrightarrow \rightarrow$ diopsídio $+\mathrm{CO} 2+\mathrm{H}_{2} \mathrm{O}$ (4).

A primeira foi investigada experimentalmente por Boettcher (1970) e seus resultados para a anortita pura acham-se reproduzidos na figura 7. A redução do teor de anortita, no entanto, deve provocar o deslocamento da curva para a esquerda, em direcão a temperaturas mais baixas (Winkler 1977 p. 185, Mueller \& Saxena 1977 p. 193). Embora este efeito seja pequeno, deve ser considerado na interpretação das condições de pressão e temperatura do metamorfísmo MI, já que o plagioclásio das rochas cálcio-silicáticas é bytownita.

A segunda, mais complexa e envolvendo sistemas divariantes, foi estudada por Metz (1970) e Metz \& Puhan $(1970,1971)$, por meio de procedimentos experimentais a
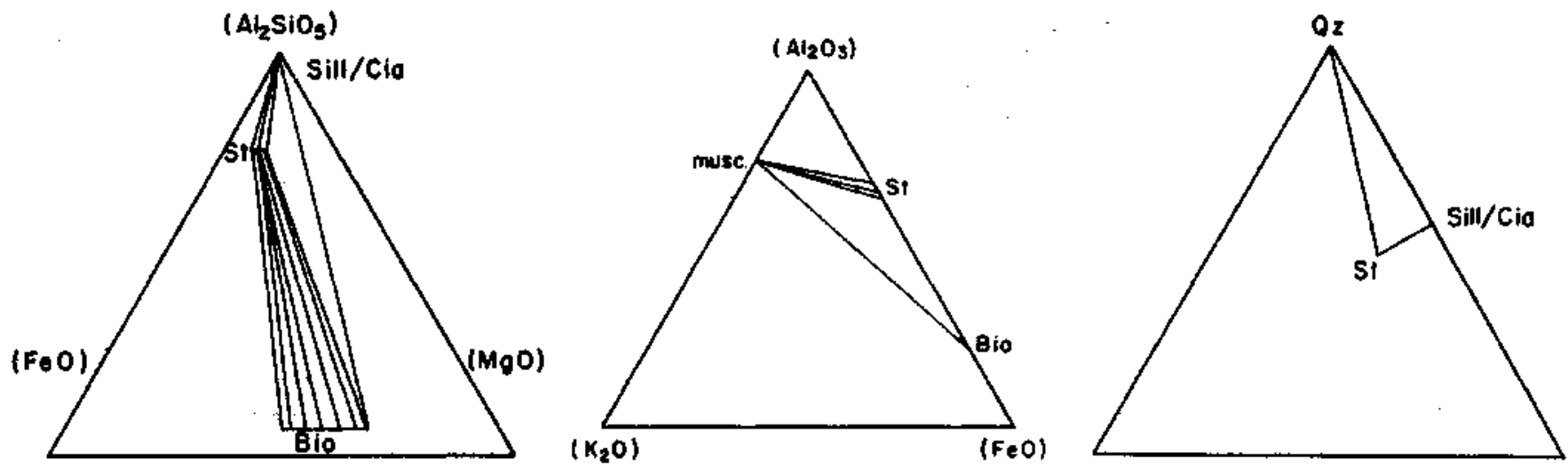

Figura 5 - Representação em diagrama AKF e A'FM de parageneses envolvendo estaurolita \pm biotita \pm cianital sillimanita \pm muscovita, compatíveis com o fácies anfibolito, descritas nos xistos tipo Santa Rita

Figure 5 - AKF and AFM diagram representations of parageneses involving "staurolite \pm biotite \pm kyanite/sillimanite \pm muscovite", described in the Santa Ritaschists and compatible with amphibolite fades metamorr ${ }^{\text {u: }}$ "ondition 

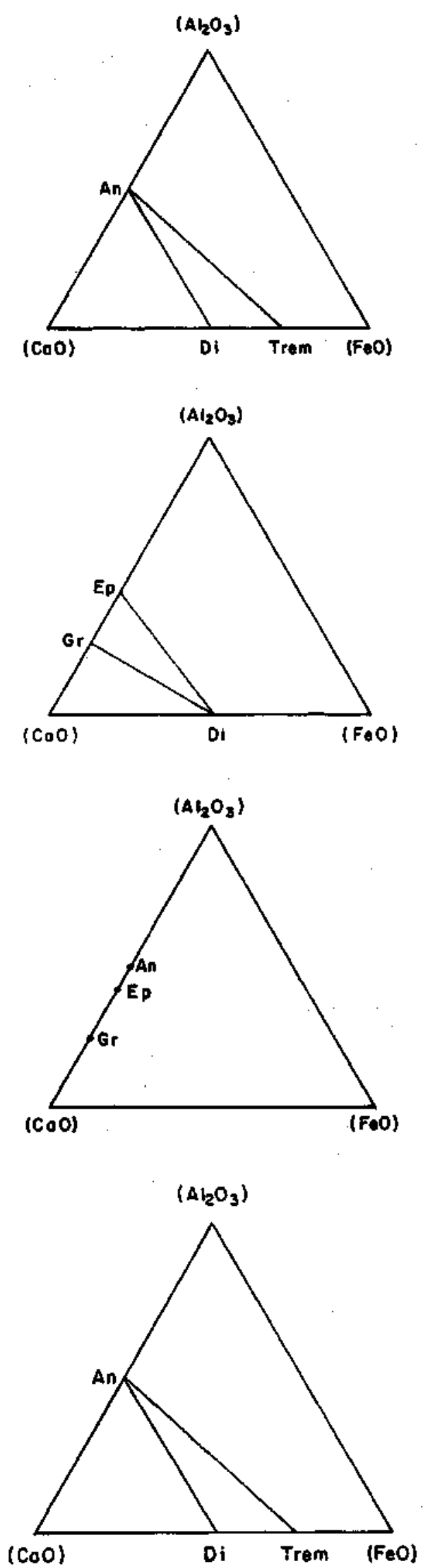
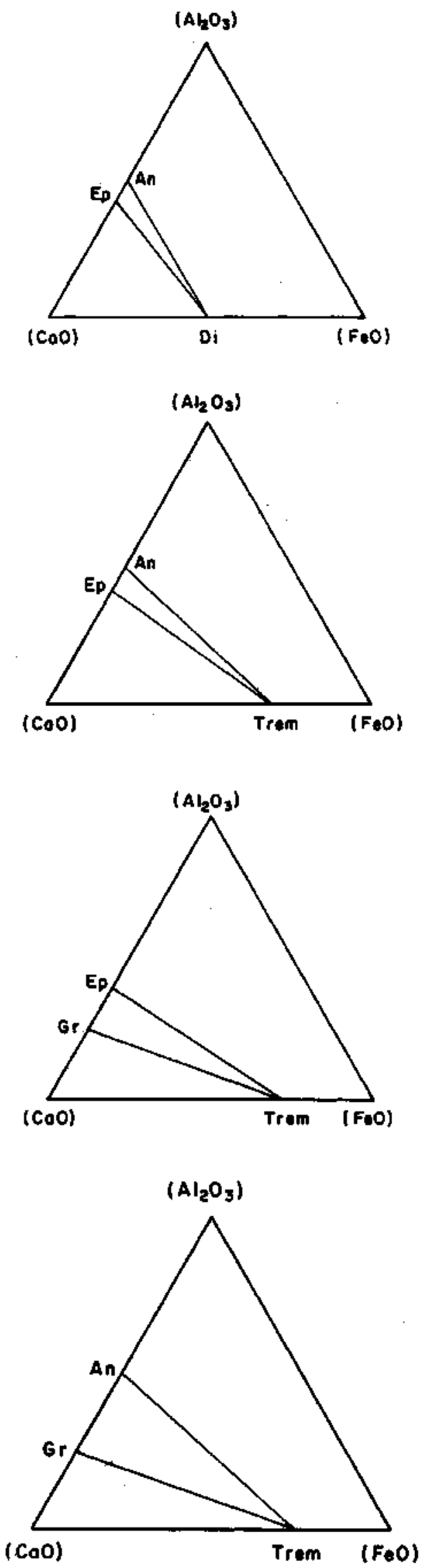

Figura 6 - Representação em diagrama ACF de parageneses envolvendo anortita \pm epídoto \pm tremolita \pm diopsídio \pm calcita \pm granada, possíveis nos limites do fades anfibolito e descritas nas rochas cálcio-silicáticas intercaladas aos xistos Santa Rita Figure 6 - ACF diagram representation of parageneses involving "anorthite \pm epidote \pm tremolite \pm diopside \pm calcite \pm garnet", possible inside the amphibolite-facies boundaries and described in calc-silicate rocks intercaleted to the Santa Rita schists 


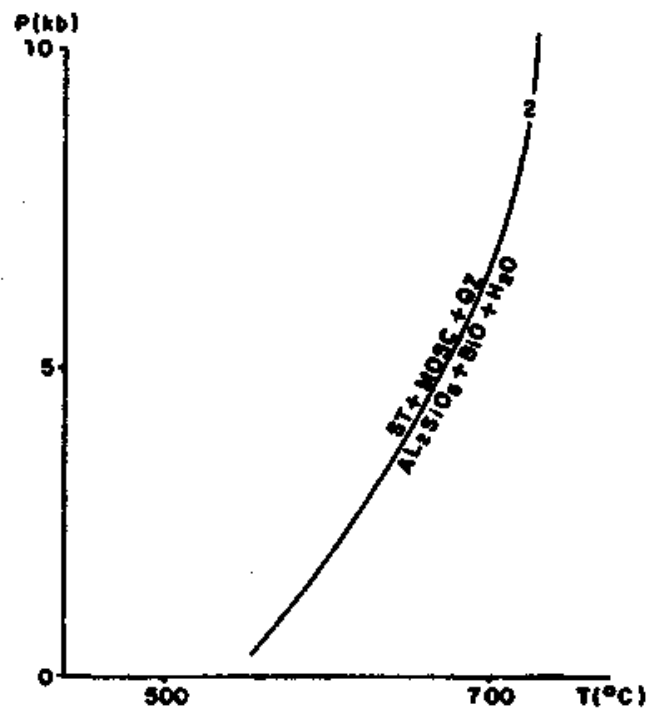

Figura 7 - Curvas- Um ites para os intervalos de temperaura e pressão vigentes durante o metamorfismo regional $M_{I}$ que atuou sobre as rochas da região de Embu-Guaçu-Parelheiros. A área assinalada representa as condições mais prováveis para o pico deste evento

Figure 7 - Limitativy curves forthe temperature and pressure intervals which prevailed during the $\mathrm{M}_{1}$ regional metamorphism, overprinted on rocks from Embu-Guacu-Parelheiros region, the outl ined area indicates the most probable peak conditions for this event

pressão constante e com variação de temperatura e da fração molar de $\mathrm{CO}_{2}$. A partir desses trabalhos, verificou-se que a reação de formação de diopsídio às expensas de tremolita, calcita e quartzo ocorre em um pequeno intervalo de temperatura, mesmo com grande variação da fração molar de $\mathrm{CO}_{2}$, o que permite tratá-la, aproximadamente, como um sistema univariante, pouco dependente da pressão parcial de fluidos. A curva média desse equilíbrio, também representada na figura 7, é praticamente coincidente com a de decomposição da estaurolita em presença de quartzo e muscovita (reação 2).

Integrando essas curvas com a de geração da estaurolita a partir de clorita e muscovita (Hoscheck 1969), é possível admitir, para o pico do metamorfismo regional progressivo MI, temperatura situada dentro do intervalo máximo entre $575^{\circ}$ a $700^{\circ} \mathrm{C}$, correspondendo, provavelmente, a valores mais próximos do limite superior.

A existência de cianita estável nos xistos dos arredores de Santa Rita pode indicar os valores mínimos para a pressão vigente durante $\mathrm{M}_{\text {. }}$

Embora muitos experimentos tenham sido realizados para a determinação do ponto triplo do sistema "cianita-andaluzitasillimanita", sua localização permanece incerta. Isto se deve a dificuldades experimentais e a problemas relacionados à própria estrutura dos aluminossilicatos (Zen 1969, Holdaway 1971), como a presença de água na estrutura dos $\mathrm{Al}_{2} \mathrm{SiO}_{5}$ sintéticos e variações composicionais dadas pela substituição de parte do $\mathrm{Al}$ por $\mathrm{Fe}$ e/ou $\mathrm{Mg}$.

Além disso, a lentidão das reações entre os polimorfos (Deer et al. 1982) e o fato de serem refratários (Chinner 1966) dificulta a nucleação e a transformação, possibilitando a persistência metaestável das espécies de $\mathrm{AI}_{2} \mathrm{SiO}_{5}$ fora de seus campos de estabilidade.

De acordo com Schuiling (1962 apud Althaus 1967) e Winkler (1965 apud Althaus 1967), o ponto triplo deve situarse fora do campo de estabilidade da pirofilita, já que somente andaluzita ou cianita resultam de sua quebra que ocorre em intervalo entre $400^{\circ} \mathrm{C}$ e $500^{\circ} \mathrm{C}$ apressões que variam de $1 \mathrm{kbar}$ a $10 \mathrm{kbar}$. Assim, valores de temperatura para o ponto triplo menores que $400^{\circ} \mathrm{C}$ ou $500^{\circ} \mathrm{C}$, tais como os determinados por Clark et al. (1957), Miyashiro (1961), Bell (1963), Khitarov et al. (1963), Weill (1966) e Holm \& Kleppa (1966), estão em desacordo com as observações petrográficas.

Também o cloritóide coexiste freqüentemente com andaluzita e cianita sendo rara, porém, sua associação com sillimanita, até agora somente descrita por Ganguly (1969). Embora esse autor tenha considerado a associação cloritóide/ andaluzita estável, reconheceu o fato de que sua ocorrência em terrenos pplimetamórficos dificulta o entendimento das relações entre estes dois minerais. Tendo por base estas considerações, pode-se concluir que o ponto invariante no sitema $\mathrm{Al}_{2} \mathrm{SiO}_{5}$ está localizado fora do campo de estabilidade do cloritóide, embora seja admissível pequena superposição. Aceitando os valores entre $3 \mathrm{kbar}$ e $10 \mathrm{kbar}$ para pressão e $600^{\circ} \mathrm{C}$ para a temperatura determinados por Hoscheck (1969) para $p$ equilíbrio da reação que marca o limite superior de estabilidade para o cloritóide, pontos triplos como os de Fyfe \& Turner (1966) e Holdaway (1971) tornam-se inválidos.

A curva de Richardson et al. (1968) para a interface sillimanita/andaluzita intercepta a curva de anatexia para 0 sistema granítico, contrariando a evidência de andaluzita instável em áreas migmatíticas. No entanto, segundo Holdaway (1971), os valores obtidos por Richardson et al. (1968) devem estar deslocados em mais de $100^{\circ} \mathrm{C}$ em direção a temperaturas mais elevadas, devido à utilização nos experimentos de amostras com sillimanita fibrosa que, altamente reativa, promove o crescimento de andaluzita no campo de estabilidade da sillimanita. O mesmo ocorre com a determinação de Althaus (1967).

Porém, mesmo com estas restrições, mas com base nas associações paragenéticas naturais, é possível considerar o valor de $600^{\circ} \mathrm{C}$ a 5,5 kbar, média entre o de Richardson et al. (1968) e de Althaus (1967), como o que mais se aproxima do valor real para o ponto triplo.

Ao mesmo tempo que os cálculos termodinâmicos efetuados por Powell \& Rolland (1990) dão respaldo ao valor aqui adotado, seu desacordo com os obtidos por Berman et al. (1989), também termodinâmicos, mostram que a polêmica existente sobre a localização do ponto invariante no sistema $\mathrm{Al}_{2} \mathrm{SiO}_{5}$ está longe de ser resolvida.

Assim, a presença de cianita estável nos xistos de EmbuGuaçu - Parelheiros indica que durante o metamorfismo MI houve uma elevação de pressão até, no mínimo, 5,5 kbar, podendo posteriormente ter permanecido constante ou ter sofrido pequeno decréscimo na época de geração da sillimanita, de modo a permitir associações estáveis ou metaestáveis envolvendo os dois aluminossilicatos.

A integração das curvas que delimitam o campo de estabilidade da estaurolita - e que coincidem com os limites para o intervalo máximo de temperatura admitido para o evento Mi com a curva de estabilidade da cianita no sistema $\mathrm{Al}_{2} \mathrm{SiO}_{5}$ equivalente às pressões mínimas para este episódio (Fig. 7) mostra que as condições de pressão e temperatura para 0 metamorfismo progressivo sobre os xistos "Santa Rita" situaram-se entre $575^{\circ} \mathrm{C}$ e $700^{\circ} \mathrm{C}$ a, aproximadamente, 5,5 kbar.

Metamorfismo metassomático $\mathrm{M}_{2} \mathrm{O}$ metamorfismo metassomático $\mathrm{M}_{2}$ é expresso por muscovita, sillimanita fibrosa e turmalina relacionadas à ação de fluidos residuais magmáticos sobre os xistos encaixantes. Estes minerais se superimpõem à assembléia de Mi (biotita, cianita, estaurolita, granada, síllimanita e muscovita), crescendo discordantemente à foliação principal da rocha.

A muscovita é porfiroblástica, com inclusões de cianita, sillimanita e sillimanita fibrosa deformada, meandrante nas folhas de mica. A sillimanita fibrosa é encontrada também como inclusão no quartzo, intercrescida com biotita e em locais de pressão elevada, como na interface entre minerais ou em kink bands. 


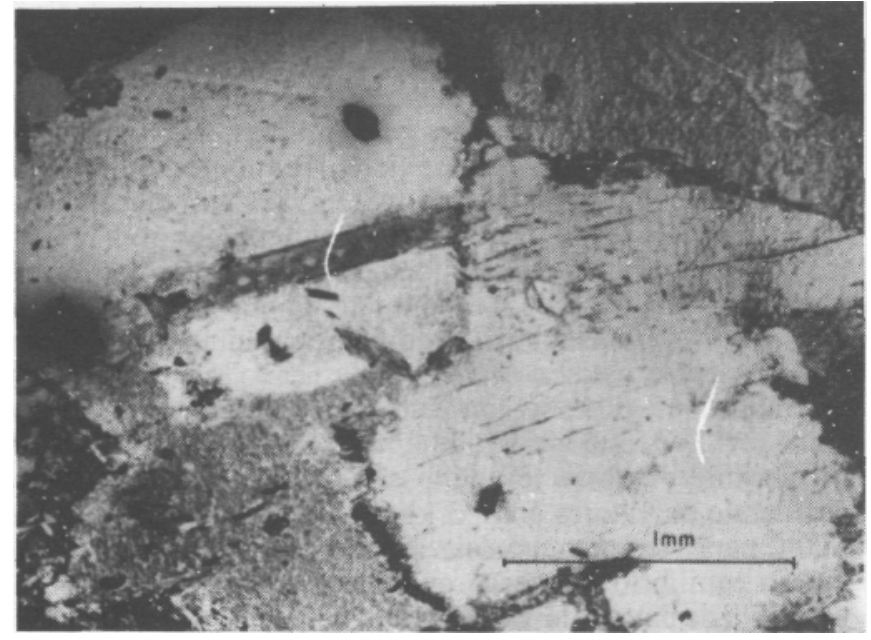

Fotomicrografia 1 - Amostra de micaxisto da Seqüência tipo Santa Rita, exibindo grãos de muscovita com contatos marcados pela presença de sillimanitafibrosa. Polarizadores cruzados

Photomicrograph 1 - Micaschist sample from the Santa Rita type sequence, exhibiting muscovite grains with their centals marked by the presence

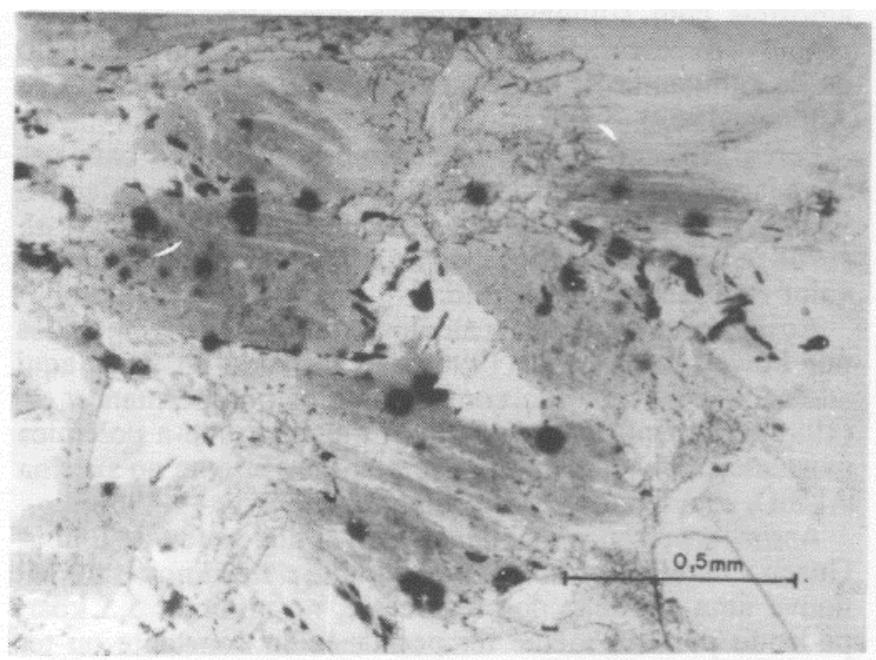

Fotomicrografia 3 - Substituição parcial de biotita por sillimanitafibrosa, que cresce segundo as direções de clivagem do mineral primário. Amostra de xisto "Santa Rita". Polarizadores paralelos

Photomicrograph 3-Partial substitutionofbiotite by fibrous sillimanite, which grows following the cleavage directions of the previous mineral Santa Rita Schist sample. Parallel nicols

Turmalina bem cristalizada cresce preferencialmente em zonas de alívio de pressão, como nas linhas de charneira de microdobras da foliação principal, caracterizando uma lineação mineral.

A "fibrolita" freqüentemente é tida como variedade fibrosa de sillimanita. Estudos de Bell \& Nord (1974), porém, demonstraram que ela é, na verdade, um intercrescimento submicroscópico de sillimanita e quartzo.

Como na área estudada coexistem sillimanita fibrosa ou "fibrolita" e sillimanita não-fíbrosa, a primeira questão que surge refere-se a contemporaneidade ou não entre estes minerais.

Critérios microestruturais (Vernon \& Flood 1977) permitem concluir que a sillimanita fibrosa é posterior à assembléia gerada em MI, incluindo parte do quartzo e muscovita, estaurolita, cianita e sillimanita prismática e, cogenética à

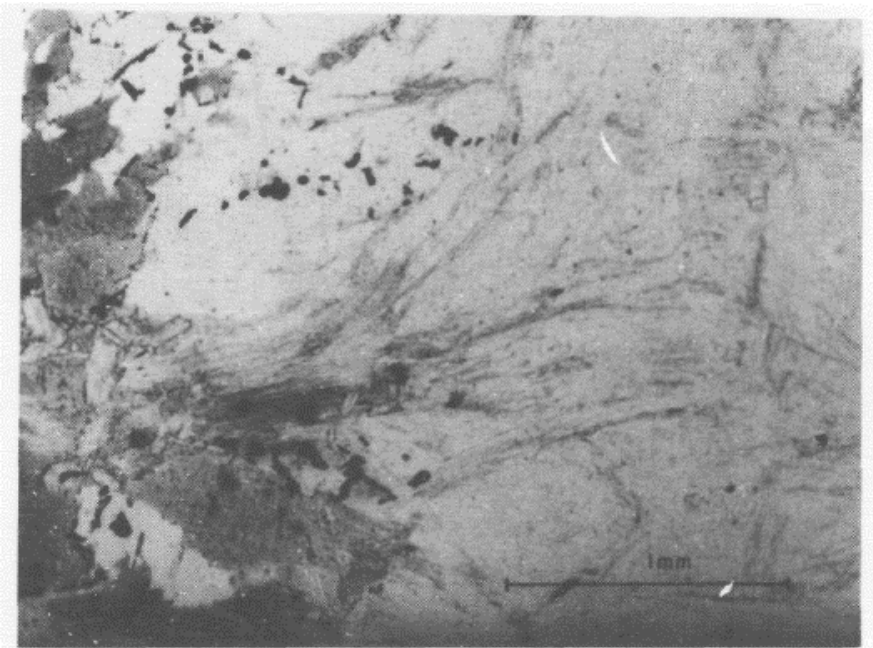

Fotomicrografia 2 - Micaxisto tipo Santa Rita com feixe de sillimanitas fibrosas formadas por substituição de biotita, irradiadas em direção à muscovita. Polarizadores paralelos Photomicrograph 2 - Santa Rita type micashist with fibrous sillimanite sheafs, formed through substitution of biotite, and irradiating towards muscovite. Parallel nicols

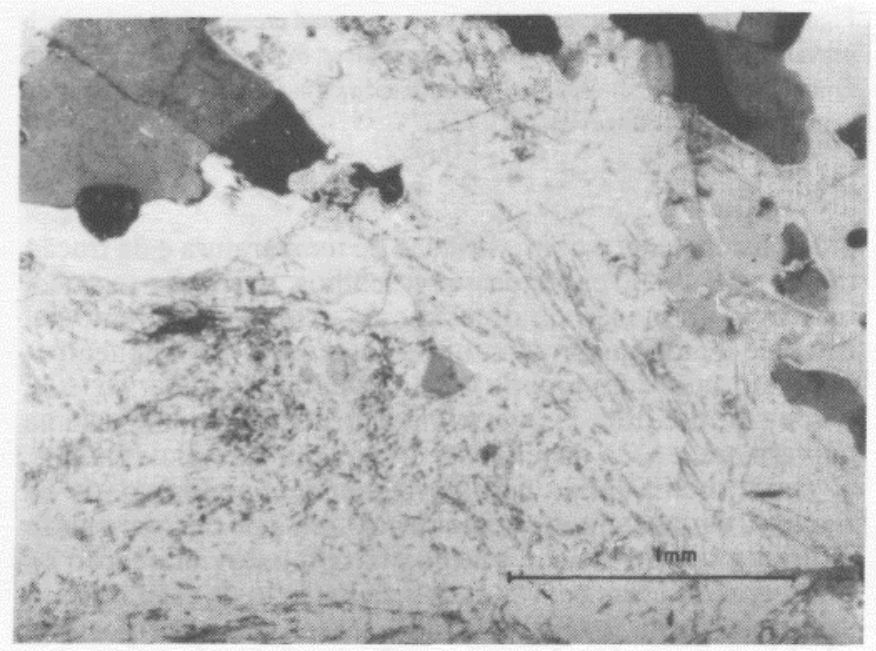

Fotomicrografia 4 - Amostra de micaxisto com sillimanita fibrosa inclusa em muscovita e quartzo, não exibindo deflexão das fibras na passagem de um grão para outro Photomicrograph 4- Micashist sample with fibrous sillimanite included both in muscovite and quartzwithout exhibiting deflection when passing from one grain to the other. Crossed nicols

muscovita, turmalina e quartzo formados em $\mathrm{M}_{2}$. Entre as feições diagnosticas podem-se destacar: a. concentração de sillimanita fibrosa nos contatos entre minerais ou em zonas de incremento de stress como, por exemplo, em zonas de kink bands (Fotomicrografia 1); b. ocorrência de fibras irradiadas a partir de um feixe em direção a outros minerais (Fotomicrografia 2); c. crescimento de sillimanita fibrosa em biotita, obedecendo sua direção de clivagem (Fotomicrografia $3)$; d. sillimanita fibrosa inclusa em grãos de muscovita e quartzo e/ou passando de um mineral para outro sem deflexão da direção das fibras (Fotomicrografia 4).

As texturas a e b são próprias de sillimanita fibrosa desarmônica, posterior aos minerais aos quais está associada. Feições como as descritas no item c poderiam resultar de nucleação epitaxial (Chinner 1961) ou, como em d, poderiam ser produzidas por meio de crescimento simultâneo. 


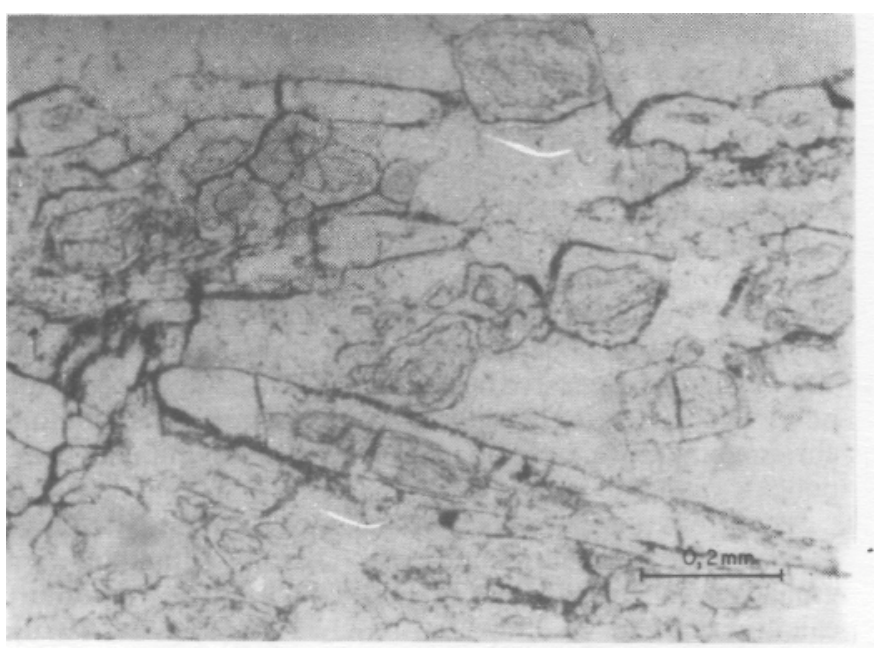

Folomicrografia 5 - Sillimanita prismática com bordas serie it izadas. Amostra de xisto "Santa Rita". Polarizadores paralelos

Photomicrograph 5- Prismatic sillimanite with sericitized outlines Santa Rita micaschist sample. Parallel nicols

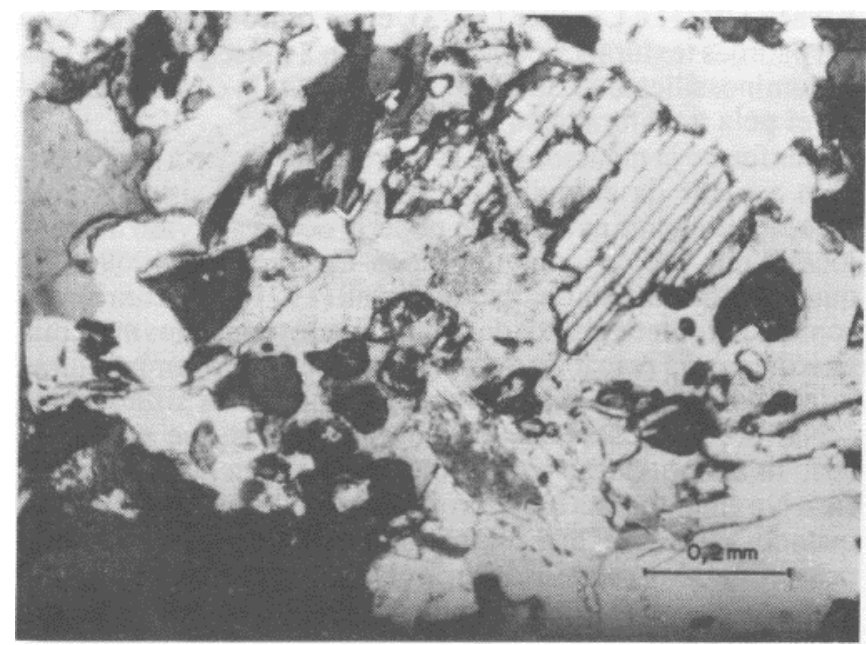

Fotomicrografia 7 - Rocha cálcio-silicática exibindo plagioclásio parcialmente substituído por epídoto. Polarizadores cruzados

Photomicrograph 7 -Calc-silicate rockexhibitingplagioclase partially substituted by epidote. Crossed nicols

Nos xistos de Embu-Guaçu-Parelheiros, os intercrescimentos de biotita e sillimanita fibrosa devem resultar da substituição de mica pelo aluminossilicato, promovida pelo aporte de íons $\mathrm{H}^{+}$ao sistema, conforme a reação 2 biotita $+14 \mathrm{H}^{+} t \rightarrow$ sillimanita fibrosa $+2 \mathrm{~K}^{+}+6(\mathrm{Mg}, \mathrm{Fe})^{2+}+9 \mathrm{H}_{2} \mathrm{O}+5$ quartzo (5) (Vernon 1979).

$\mathrm{O}$ excesso de $(\mathrm{Mg}, \mathrm{Fe})^{2+}$ está, provavelmente, cristalizado sob a forma de minerais opacos, freqüentemente distribuídos na interface entre biotita e sillimanita fibrosa intercrescidas. $\mathrm{O}$ cátion $\mathrm{K}^{+}$liberado deve, por sua vez, reagir com cianita e quartzo, dando origem aos porfiroblastos de muscovita com inclusões de sillimanita fibrosa, segundo a reação 4 cianita +3 quartzo $+2 \mathrm{~K}^{+}+3 \mathrm{H}_{2} \mathrm{O} \longleftrightarrow \rightarrow 2$ muscovita+sillimanita $+2 \mathrm{FT}$ (6), proposta por Carmichael (1969), com base em observações texturais.

Kwaak (1971) atribui estas mesmas texturas à substituição seletiva de cianita por muscovita, em condições do campo de estabilidade da sillimanita, de acordo com a reação 3 aluminossilicato +3 quartzo $+2 \mathrm{~K}^{+}+3 \mathrm{H}_{2} \mathrm{O} \leftrightarrow \rightarrow 2$ muscovita $+2 \mathrm{H}^{+}(7)$.

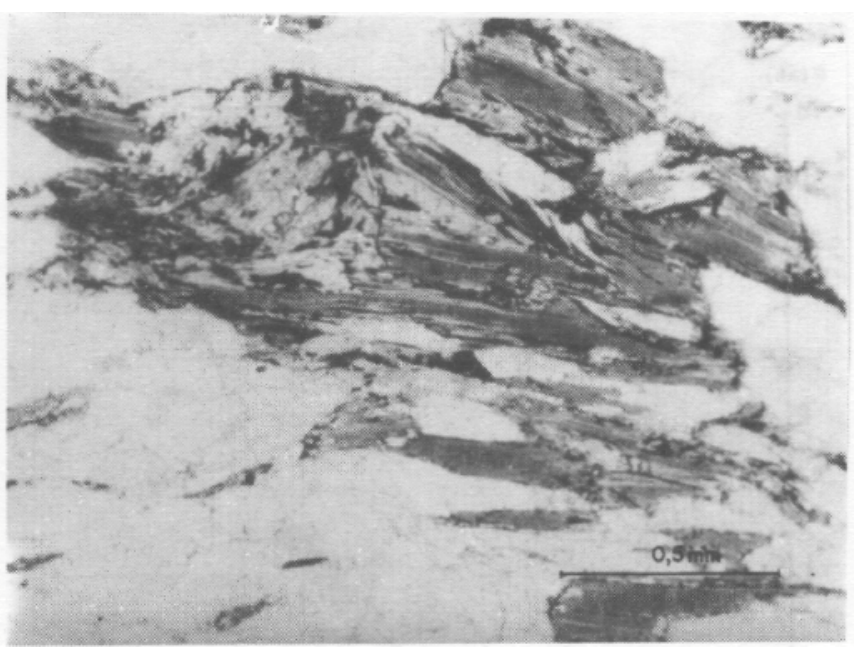

Fotomicrografia 6 - Biotita parcialmente cloritizada em amostra de xisto "Santa Rita". Polarizadores paralelos Photomicrograph 6- Partially chloritizedbiotite in a San tá Rita schist sample. Parallel nicols

A sillimanita fibrosa seria, então, anterior à cristalização da muscovita e produto do mesmo evento responsável pela geração de cianita, que teria permanecido como fase metaestável.

Esta reação não explica satisfatoriamente a presença de sillimanita fibrosa inclusa em muscovita, provavelmente resultante da cristalização simultânea, nos moldes de Carmichael (1969), mas poderia ser responsável pela textura descrita no item a. Wintsch (1975) mostrou que um aumento de pressão desloca o equilíbrio (7) no sentido da geração de aluminossilicato às expensas de muscovita. Assim, concentrações locais de pressão, como a existente em zonas de kink bands de muscovita, promoveriam sua dissolução e a nucleação de $\mathrm{Al}_{2} \mathrm{SiO}_{5}$.

Estas reações metassomáticas tomadas em uma área restrita, atuando ao mesmo tempo em uma zona relativamente mais abrangente, fecham um sistema no qual íons são liberados e consumidos, independente de agente exterior.

A presença de turmalina nestas rochas foi interpretada (Stein et al. 1986) como resultante de remobilização de boro retido no sedimento original. No entanto, se esta hipótese fosse correta, seria de se esperar sua cristalização já durante o evento MI. Porém, como isso não acontece e como há concentração de turmalina nos veios pegmatíticos, é mais viável supor uma relação genética entre estes veios e a turmalização. Assim, é provável que tenha havido aporte externo de boro durante a evolução metamórfica dos xistos de Embu-Guaçu - Parelheiros, promovido pela atividade granítica brasiliana.

Esta idéia também tem respaldo no trabalho de Ahmad \& Wilson (1982), que verificaram aumento nos teores de U e B em uma assembléia com sillimanita fibrosa (interpretada como metassomática), em relação à anterior, produto de metamorfismo regional progressivo, onde ocorre sillimanita; no trabalho de Shmakin (1983), que detectou anomalias positivas para o boro em auréolas de muscovitização no contato entre corpos pegmatíticos e a encaixante; e por Kretz et al. (1989). Ainda, de acordo com Michel-Lévy (1950apud Pitcher \& Read 1963), o boro atuaria como catalizador na síntese de sillimanita fibrosa, o que também explicaria a abundância desse mineral nos xistos de Embu-Guaçu Parelheiros.

Vários autores, como Chinner (1973), Vernon (1979), Carmichael (1969), Vrána (1973), Wintsch (1975), Ahmad \& Wilson (1982) e Kretz et al. (1989), apontam o metassomatismo 


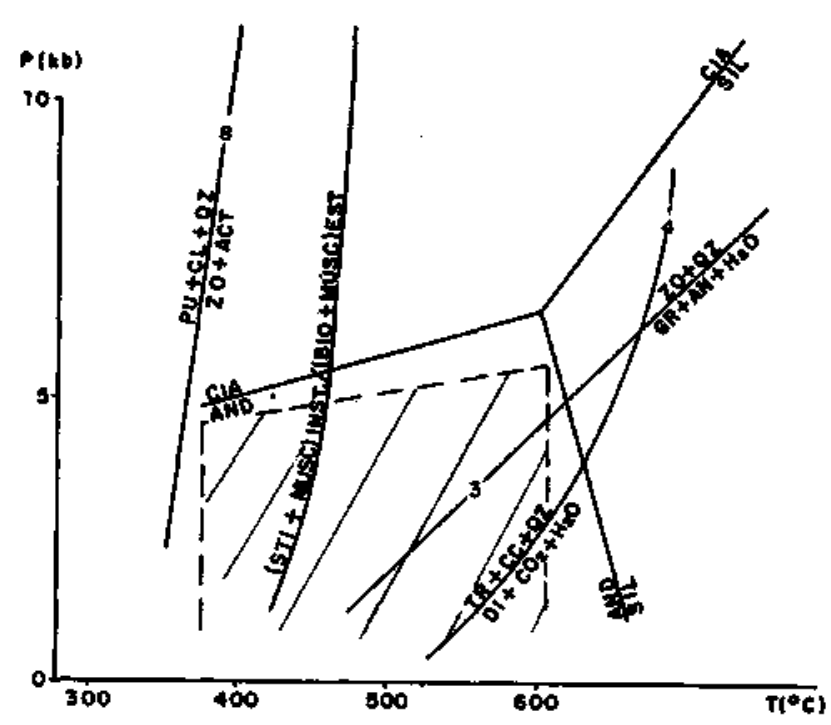

Figura 8 - Curvas de equilíbrio para as reações que representam as transformações e as condições de pressão $e$ temperatura para o metamorfismo retrógrado $M_{1}$. A área assinalada corresponde às condições prováveis depressão e temperatura vigentes durante este episódio Figure 8 - Equilibrium curves forthe reactions which representthe transformations and temperature-pressure conditions during the $\mathrm{M}$, retrogressivemetamorphism. The outl ined area indicates the probable pressure-temperature range prevail ing during this episode

como gerador de aluminossilicatos e muscovita tardios, associados ou não a turmalina e, em geral, relacionado à atuação de soluções aquosas residuais em eventos magmáticos e de migmatização. Quimicamente, este processo é semelhante à alteração hidrotermal (Hemley \& Jones 1964), sendo seu caráter determinado pelos álcalis e voláteis. Seja qual for o cátion, os parâmetros que controlam o processo são pressão, temperatura e composição da fase fluida, que pode ser expressa pela atividade ou pela concentração termodinâmica de íons. O sentido da reação é dado pela razão entre a atividade do cátion produzido e do cátion consumido. Deste modo, $\mathrm{a}_{\mathrm{k}}{ }^{+} /$ $\mathrm{a}_{\mathrm{H}}^{+}$elevada fará com que a reação (6) opere no sentido da geração de muscovita e sillimanita, ou seja, no sentido do consumo de íons em excesso.

Assim, é provável que a gênese de muscovita, sillimanita fibrosa e turmalina em $\mathrm{M}_{2}$ tenha sido propiciada pela ação de uma solução aquosa ácida ( $\mathrm{pH}$ baixo), potássica, rica em boro, em condições de pressão e temperatura compatíveis com as de estabilidade da sillimanita.

A aceitação desta hipótese implica a revisão dos dados geocronológicos existentes para os metassedimentos que ocorrem na área. Isso porque, conforme Dickin \& Jones (1983), Shearer et al (1984), Brewer \& Atkin (1989), entre outros, a atividade granítica e os pegmatitos e fluidos a ela relacionados provocam alterações nas relações $\mathrm{Rb}-\mathrm{Sr}$ e K-Ar iniciais, invalidando a premissa de sistema fechado.

Também, a identificação de minerais neoformados, provavelmente devido à ação destes fluidos ou mesmo de um evento termal, superimpostos àqueles gerados em um episódio anterior, torna temerária a utilização de quaisquer análises geocronológicas feitas em rocha total. Este é justamente o caso da determinação feita para xistos "Santa Rita", dos arredores de Embu-Guaçu, que resultou em idade de $750+20 \mathrm{Ma}$ (Vieira \& Tassinari 1988).

Metamorfismo retrógrado $\mathbf{M}_{3}$ Ometamorfismoretrógrado $\mathrm{M}_{3}$ representa a adaptação das assembléias de alta pressão e temperatura geradas durante o evento Mi a condições mais brandas. Está caracterizado na área pela saussuritização dos feldspatos e plagioclásios das rochas graníticas, pela sericitização da sillimanita dos xistos (Fotomicrografias 5) e pela cloritização da biotita, tanto dos xistos quanto dos granitóides (Fotomicrografia 6).

No entanto, é nas rochas cálcio-silicáticas que este episódio se torna mais evidente pelas substituições de diopsídio, plagioclásio, tremolita e granada por epídoto (Fotomicrografia 7) e de diopsídio por tremolita.

O caráter retrogressive do metamorfismo pôde ser deduzido pelas feições texturais e por parâmetros químicos, como o enriquecimento relativo do plagioclásio (bytownita) no componente albita.

As reações que expressam $\mathrm{M}_{3}$ nas rochas cálcio-silicáticas, já discutidas anteriormente, são: zoisita + quartzo $<=>$ granada + anortita $+\mathrm{H}_{2} \mathrm{O}(3)$ (Boettcher 1980) e tremolita + calcita + quartzo $\leftarrow \rightarrow$ diopsídio $+\mathrm{CO}_{2}+\mathrm{H}_{2} \mathrm{O}$ (4) (Metz 1970).

As transformações observadas nas rochas cálcio-silicáticas apontam em direção a temperaturas inferiores às dadas pela curva que define o equilíbrio "diopsídio + calcita + tremolita + quartzo", sendo que a maior parte delas representa condições ainda mais brandas, equivalentes às que permitem a coexistência estável de zoisita e quartzo.

A substituição de sillimanita por sericita foi estudada por Kwaak (1971) e Chinner (1973), entre outros que, com base em padrões texturais, apontam a reação 2 muscovita $+2 \mathrm{H}^{+}<=$ 3 aluminossilicato +3 quartzo $+2 \mathrm{~K}^{+}+3 \mathrm{H}_{2} \mathrm{O}$ (7) como a responsável pela transformação.

Conforme já mencionado, este processo poderia ser produzido a partir da entrada de íons potássio no sistema, pela atuação de agente externo, ou poderia ocorrer devido a trocas locais, nos moldes sugeridos por Carmichael (1969). De qualquer forma, como salientou Kwak (1971), a quebra iônica somente acontece abaixo da instabilidade termal dos minerais envolvidos na reação, o que, neste caso, sugere temperaturas inferiores às necessárias para a estabilidade da sillimanita.

Nas seções observadas não há evidências que permitam atribuir a cloritização parcial da biotita a uma reação específica. No entanto, esta transformação só deve ter se processado quando a pressão e a temperatura atingiram valores que possibilitaram a estabilização da clorita às expensas da biotita, o que corresponde, grosso modo, à interface entre as zonas da biotita e clorita.

Segundo Winkler (1977, p. 180), este limite pode ser representado pelo grau de isorreação "(estilpnomelano + muscovita) instável/(biotita + muscovita) estável" que é um equilíbrio pouco dependente da pressão e que ocorre em um intervalo de temperatura entre $400^{\circ} \mathrm{C} \mathrm{e} 450^{\circ} \mathrm{C}$ (Fig. 8).

Estes resultados são concordantes com os inferidos através das associações descritas nas rochas cálcio-silicáticas.

Assim, é provável que as condições durante o metamorfismo retrógrado $\mathrm{M}_{5}$ tenham sido semelhantes às do campo de estabilidade da andaluzita, que compreende os equilíbrios discutidos e que também explicaria a alteração da cianita dos xistos de Embu-Guaçu - Parelheiros.

A presença de epídoto como mineral estável nestas assembléias indica que a temperatura mínima para este evento deve ter sido próxima a $300^{\circ} \mathrm{C}$, independente da pressão, que são as condições exigidas para o equilíbrio da reação pumpellyíta + clorita + quartzo $<=>$ zoisita + actinolita (8) (Fig. 8), que marca o limite entre ps graus incipiente e fraco, já que temperaturas inferiores a esta implicariam sua desintegração.

Portanto, a partir dos dados petrpgráficos, é possível restringir o metamorfismo retrógrado a um intervalo máximo de temperatura entre $300^{\circ} \mathrm{C} \mathrm{e} 600^{\circ} \mathrm{C}$ e pressões menores que 5,5 kbar (Fig. 8).

Metamorfismo dinâmico $\mathbf{M}_{4} \mathrm{O}$ metamorfismo dinâmico $\mathrm{M}_{4}$ é bastante restrito e, pelas próprias características das rochas da região, mais explícito nos granitos e gnaisses. 
As modificações promovidas por este evento foram pouco intensas e correspondem, basicamente, à quebra de grãos de quartzo e feldspato e ao desenvolvimento da foliação dada pelo estiramento destes minerais segundo a direção principal do esforço, provocadas pela movimentação ao longo de falhamentos de pequena expressão na área mapeada.

CONCLUSÕES O conjunto de observações realizadas, aliado aos dados da bibliografia existente, permitem concluir que: - a área foi afetada por quatro episódios de metamorfismo: o primeiro, de caráter regional e progressivo; o segundo, metassomático; o terceiro, retrógrado; o quarto, dinâmico. - o evento regional e progressivo MI atingiu suas condições mais drásticas a temperaturas situadas no intervalo máximo entre $575^{\circ} \mathrm{C}$ e $700^{\circ} \mathrm{C}$ com pressões acima de $5,5 \mathrm{kbar}$, tendo seu pico a temperaturas provavelmente mais próximas do limite superior. As pressões estimadas para este episódio correspondem, grosso modo, a soterramento da ordem de $17 \mathrm{~km}$. - o segundo episódio, um metamorfismo metassomático, deve ter sido promovido pela ação de soluções aquosas ácidas ( $\mathrm{pH}$ baixo), ricas em boro e potássio, em condições de pressão e temperatura do campo de estabilidade da sillimanita, sobre a assembléia aluminosa gerada em $\mathrm{M}_{1}$.

- o terceiro evento, de caráter retrógrado, uma resposta das assembléias de pressão e temperatura mais elevadas ao resfriamento regional, teve temperaturas mínimas ao redor de $300^{\circ} \mathrm{C}$ a pressões menores que $5,5 \mathrm{kbar}$, que são condições compatíveis com as de estabilidade da andaluzita.

- o quarto episódio corresponde às transformações estruturais e texturais das rochas submetidas a deformação rúptil, relacionadas aos falhamentos transcorrentes que ocorrem na área.

Agradecimentos Este trabalho teve o suporte financeiro da Fundação de Auxílio à Pesquisa do Estado de São Paulo (FAPESP) (processo Geologia 85/0899-1) e do Conselho Nacional de Desenvolvimento Científico e Tecnológico (CNPq) (processo 407051/87-2GL/FV). À CESP, os autores agradecem a cessão dos testemunhos de sondagens rotativas.

\section{REFERÊNCIAS BIBLIOGRÁFICAS}

AHMAD, R. \& WILSON, C.J.L. 1982. Microstmcturalrelationsof sillimanite and "fibrolite" of Broken Hill, Australia. Lithos, 15:49-58.

ALTHAUS, E. 1967. The triple point andaluzite-sillimanite-kyanite. An experimental and petrologic study. Contrib. Mineral. Petrol,, 16:29-44.

BELL, P.M. 1963. Aluminium silicate system: experimental determination of the triple point.Science, 139:1055-1056.

BELL, P.M. \& NORD, G. 1974. Microscopic and electron diffraction on study of fibrolitic sillimanite./4wi. Rept. Dir. Geophys. Lab., 74:444-448.

BERMAN, R.G. 1988. Internally consistent thermodynamic data for minerals in the system NazO-KzO-CaO-MgO-FeO-FesO-ALjO-SiO-rTiCh-^ ${ }^{\wedge}-$ $\mathrm{CO}_{2 .}$. J. Petrol., 29(2):445-522.

BOETTCHER, A.L. 1970. The systemCaO- $\mathrm{AI}_{2} \mathrm{Oi}-\mathrm{SiO}_{2}-\mathrm{H}_{2} \mathrm{O}$ athighpressures and temperatures. J. Petrol., l 1(2):337-379.

CAMPANHA, G.A.C.;BISTRICHI,C.A.; ALMEIDA, M.A. 1987.Consideracões sobre a organizacão litoestratigráficae evolucão tectônica da faixa dedobramentosApiaí. In: SIMP. SUL-BRAS.GEOL.,3.Curitiba, 1987. Atas... Curitiba, SBG. v. 2, p. 725-742.

CARMICHAEL, D.M. 1969. On the mecanism of prograde metamorphic reactions in quartz-bearing pelitic rocks. Contrib. Mineral. Petrol., 20:244267.

CHINNER, G.A. 1961. The origin of sillimanite in Glen Clova, Angus. $J$. Petrol.,2(3):312-323.

CHINNER, G.A. 1973. The seletive replacement of aluminium silicates by white mica: A comment Contrib. Mineral. Petrol. 41:83*87.

CLARK, S.P.; ROBERTSON, E.G.; BIRCH, F. 1957. Experimental determination of kyanite-sillimanite equilibrium relations at high temperature and pressures. Am. Sci., 255:628-640.

COUTINHO, J.M.V. 1972. Petrologia do Pré-Cambriano de São Paulo e arredores. Boi. IG/USP, 3:5-99.

DEER, W.A.: HOWIE, R.A.: ZUSSMAN, J. 1982. Rock-Forming Minerals. v. IA (Orthossilicates). 2 ed. London and New York, Longman.

DICKIN, A.P. \& JONES, N.W. 1983. Relative elementar mobility during hydrothermal alteration of abasic sill, Isle of Skye, N. W. Scotland. Contrib. Petrol.,S2:141-153.

FYFE, W.S. \& TURNER, F.J. 1966. Reappraisal of the metamorphic facies concept. Contrib. Mineral. Petrol., 12:354-364.

GANGULY, J. 1969. Chloritoid stability and related paragenese. Theory, experiments and applications. Am. J. Sci.. 267:910-944

GANGULY, J. 1972. Staurolite stability and related parageneses, theory, experiments and applications. J. Petrol., 13(2):335-365.

HASUI, Y. 1973. Tectônica da Área das Folhas de São Roque e Pilar do Sul. São Paulo. 190 p. (Tese de Doutoramento, IG/USP).

HASUI, Y.; ALMEIDA. F.F.M.: BRITO NEVES, B.B. 1978. As estruturas brasilianas. In:CONGR. BRÁS. GEOL., 30. Recife, 1978. Anais... Recife, SBG. v. 6, p. 2423-2437.

HASUI, Y.\&SADOWSKI,G.R.1976.Evoluçãogeológicado Pré-Cambriano na região sudeste do Estado de São Paulo. Rev. Bras. Geoc. 5(4):257-266.

HEMLEY, L.L. \& JONES, W.R. 1964. Chemical aspects of hydrothermal alteration with emphasis on hydrogen metasomatism. Econ. Geo/., 59:538569.

HOLDAWAY, M.J. 1971. Stability of andalusite and the aluminium silicate phase diagram. Am. J. Sci., 271:97-131.

HOLM, J.L. \& KLEPPA, O.J. 1966. The thermodynamic properties of the aluminium silicates, $4 \mathrm{~m}$. A///J., 51:1608-1622.

HOSCHECK, G. 1969. The stability of staurolite and chloritoid and their significance in metamorphism of pelitic rocks. Contrib. Mineral. Petrol., 22:208-232

K.HITAROV,N.I.PUGIN,V.A.CHAO,P·SLUTSKY,A.B. 1963. Relations between andalusite, kyanite and sillimanite at moderate temperatures and pressures. Geochemistry, 3( 1 ):235-244.
KRETZ, R.:HARTREE, R.; JONES, P. 1989. Metasomatic crystallization of muscovite in granite and tourmaline in schist related to pegmatite emplacemente near Yellowknife, Canada. Contrib. Mineral. Petrol., 102:191-204.

K WAK, T. A.P. 1971. The selective replacement of the aluminium silicates by white mica. Contrib. Mineral. Petrol., 32:193-210.

METZ,P. 1970. Experimentei leuntersuchung der metamorphose von kieselig dolomitschensedimenten.Co $\langle/ \mathrm{r} / 7>$. Mineral. Petrol.,28:221-250.

METZ, P. \& PUHAN, D. 1970. Experimentelle untersuchung der metamorphose von kieseligdolom|llschensed|menien. Contrib. Mineral. Petrol.,26:302314

METZ, P. \& PUHAN, D. 1971. Korrekturzurzrbeit,experimentelle untersuchug der metamorphose von kieseligdolomitischensedimenten. Contrib. Mineral. $/>\mathrm{e} / \mathrm{ro} / ., 31: 169-170$

MUELLER, R.F. \& SAXENA, K.S. 1977. Chemical Petrology. New York. Springer-Verlag. $394 \mathrm{p}$.

MIYASHIRO,A. 1961. Evolution of metamorphic belts. J. Petrol., 2:277-311.

PARISOT,J.;BONNAL,L.;SÍGOLO,J.B. 1985. Um método de endurecimento de amostras friáveis com emprego de verniz. Comparação com outros métodos. Boi. IG/USP, 16:11-14. (Série Científica).

PITCHER, W.S. \& READ, H.H. 1963. Contact metamorphism in relation to mannerofemplacementofgranitesof Donegal, Ireland. J. Gí?o/.,71(3):261 296.

POWELL, R. \& ROLLAND, T. 1990. Calculated mineral equilibria in the system KFMASH $\left(\mathrm{K}_{2} \mathrm{O}-\mathrm{FeO}-\mathrm{MgO}-\mathrm{Al}_{2} \mathrm{O}-\mathrm{SiO}_{2}-\mathrm{H}_{2} \mathrm{O}\right)$. Am. Mineral. 75:367-380.

RICHARDSON, S.W. 1968. Staurolite stability in part of the system Fe-AI-SiO-H. J. Petrol., 9(3):467-488.

RICHARDSON,S.W.;BELL,P.M.;GILBERT,M.C.1968.-Kyanite-sillimanite equilibrium between 700"C and 1.500"C. Am. J. Sci., 266:513-541.

SHEARER, C.K.; PAPIKE, J.J.; SIMON, S.B. 1986. Pegmatite-wallrock interations, Black Hills, South Dakota: Interaction between pegmatitederived fluids and quartz-mica schist wallrock. Am. Mineral, 71:518-539.

SHMAK1N, B.M. 1983. Geochemistry and origin of pegmatites. Geochem. /«termzf., 20(6): 1-8.

STEIN, D.P. 1984. Esboço da evoluçãopré-c da Folha de Pilar do Sul, SPSF.23-Y-C-IV-4. São Paulo. 148 p. (Dissertação de Mestrado, IG/USP).

STEIN, D.P.CAMPANHA G.A.C.FERNANDES, L.A. 1986 . A Formacão Perau na região de Pilar do Sul, SP. In: CONOR. BRAS. GEOL., 34. Goiânia, 1986. Anais... Goiânia, SBG. v. 2, p. 919-930.

SUGUIO, K.; COIMBRA, A.M.; CATTO,A.J. 1972. Estudo comparativo dos sedimentos e das rochas cristalinas circundantes da Bacia de São Paulo (Granulometria e minerais pesados). In: CONGR. BRÁS. GEOL., 26. Belém, 1972. Anais... Belém, SBG. p. 141-153.

VERNON,R.H. 1979. Formationoflatesillimanite by hidrogen metasomatism (Base-leaching) in some high-grade gnaisses. Lithos, 12:143-152.

VERNON, R.H. \& FLOOD, R.H. 1977. Interpretation of metamorphic assemblages containing fibrolitic sillimanite. Contrib. Mineral. Petrol., 59:227-235.

VIEIRA, S.R.S.S. 1989. Estudo Lito-Estruturalda Região de Embu-Guaçu Parelheiros, SP. São Paulo. 122 p. (Dissertação de Mestrado, IG/USP).

VIEIRA, S.R.S.S.; COUTINHO, J.M.V.; ALVES, F.R. 1990. Geologia e evolução geológica da região de Embu-Guaçu - Parelheiros, SP. Rev. Bras. Geoc., 20(1-4):277-281.

VIEIRA, S.R.S.S. \& TASSINARI, C.C.G. 1988. Estudo petrológico e geocronológico das rochas da região de Embu-Guaçu, Estado de São Paulo. In: CONGR. BRÁS. GEOL.35. Belém, 1988. Anais... Belém,SBG. v. 3, p.1391-1399.

VRANA, S. 1973. A model of aluminium silicates accretion in metamorphic rocks. Contrib. Mineral. Petrol., 41:73-82. 
WEILL, D.F. 1966. Stability relactions in the $\mathrm{AI}_{2} \mathrm{O}_{3}-\mathrm{SiO}_{2}$ system calculated from solubilities in the $\mathrm{AI}_{2} \mathrm{OrSiO}_{2}-\mathrm{NaAlF}$ system. Geochim. Cosmochim.

WINK.LER, H.G.F. 1967. Petrogenesis of Metamorphic Rocks. 2 ed. New York/Berlim, Springer-Verlag. $220 \mathrm{p}$

WINKLER,H.G.F. 19n.PetrogenesedasRochasMetamorficas.4ed. Porto Alegre, Edgard Bliicher. 254 p.

WINTSCH,R.P.1975.Solid-fluidequilibriainthesystemKAIShOs-NaAIShO6$\mathrm{AI}_{2} \mathrm{SiO} 5-\mathrm{SO}_{2}-\mathrm{H}_{2} \mathrm{O}-\mathrm{HCI} .7$. Petrol., !6(1):57-79.
ZEN, E. 1969. The stability relations of the polimorphs of aluminium silicate: A survey and some comments. Am. J. Sci., 267:297-309.

MANUSCRITO A651

Recebido em 23 de marco de 1990 Revisão do autor em 17 de março de 1992 Revisão aceita em 17 de março de 1992 